\title{
STRUCTURE AND EXTENSIONS OF THE USER INFORMATION SATISFACTION CONSTRUCT $^{27}$
}

\author{
Clive D. Wrigley \\ Faculty of Business Simon Fraser University \\ Email: cwrigley@sfu.ca \\ Don H. Drury \\ Faculty of Management McGill University \\ Email: drury@management.mcgill.ca \\ Ali F. Farhoomand \\ School of Business The University of Hong Kong \\ Pokfulam Road, Hong Kong \\ email: ali1@hkucc.hku.hk
}

\begin{abstract}
User Information Satisfaction (UIS) remains one of the most important constructs in Information Systems research. This paper investigates the application of the UIS instrument across a number of key variables including respondent characteristics. Several findings emerge from a survey of 379 IS and non-IS managers: First, the UIS factors are stable and generalizable. Second, the level of satisfaction varies quite substantially when compared to prior UIS reports, although the IS product satisfaction dominates. Third, IS managers, not surprisingly, evaluate their systems significantly higher than non-IS managers, indicating the importance of stakeholders in evaluating Information Systems success. Finally, respondents evaluate their internal systems differently than their inter-organizational systems, indicating that in the IS evaluation process system type must be considered as a moderating variable.
\end{abstract}

\section{INTRODUCTION}

The User Information Satisfaction construct has pervaded the Information Systems literature for over ten years. Delone and McLean (1992) identify 33 separate empirical studies, conducted between 1981 and 1987 that measured some aspect of the Information System (IS) success construct. In most cases user satisfaction was measured during the study. Its use, primarily as a surrogate for IS success, stems from the recognition that one of the primary stakeholders in organizations are the users themselves. With this view, user satisfaction indicates that systems' objectives are being met, thereby allowing managers to differentiate between more or less successful systems. The logical appeal to determining system success comes from two primary sources. The first comes from the belief that successful IS products lead to improved organizational performance. While the second comes from the desire to improve the process by which systems come into existence. Recently, the Software Engineering literature has placed greater research focus on the system development process in an attempt to understand the factors that lead to well built maintainable systems as well as managing the resulting process (Rombach, Ulery, \& Valett D 1992, Madhavji \& Schafer 1991). These, and other researchers, maintain that the process of developing, implementing and supporting IS in organizations is as important as the resulting product of development. Thus we see growing recognition for the need to integrate process and product measurement and evaluation (Tate, Verner \& Jeffrey 1992, Chroust, Goldmann \& Gschwandtner, 1990, Pfleeger \& McGowan 1990, Lanphar 1990).

By retrospectively looking at the development process we may begin to determine, for example, which tools and methods were more effective in coping with the enormous task of implementing IS. Establishing a linkage between measures of IS product and process, and subsequent organizational performance, while appealing, has been empirically elusive. The much more tractable task lies in the measurement of UIS.

This paper presents the results of a questionnaire survey, which replicated the UIS instrument in its entirety with added scales to measure respondent demographics and respondent evaluations of their interorganizational and intra-organizational systems. The data from this study provides the opportunity to i) compare the results to previous UIS reports and ii) investigate the role of system type and user type in the evaluation of IS success.

In the next section we will focus on the properties and application of the UIS instrument in order to develop our hypotheses. Following this we will provide background of our survey characteristics and properties. Next we will present our analysis with comparative studies and structural refinements. The final section will summarize our results and discuss their implications.

\footnotetext{
27 The support of the EDI Council of Canada (EDICC) and the Canadian Information Processing Society (CIPS) in providing their membership lists is greatly appreciated.
} 


\section{CONCEPTUAL DEVELOPMENT}

UIS instruments have undergone extensive revision since their inception. Gallagher (1974) developed an instrument to ascertain the value of information output, focusing solely on the IS product. The Bailey and Pearson (1983) instrument contained 39 scales which were factor analyzed into four or five factors. Ives and Olson (1983) further reduced Bailey and Pearson's questionnaire into 13 scales which resulted in three factors. This version of the instrument has been replicated in at least five independent studies (Joshi 1990, Galletta \& Lederer 1989, Baroudi \& Wanda 1988, Montazemi 1988, Raymond 1987). These three factors have been labelled:

1. Information Product

2. MIS/EDP staff and services

3. User knowledge and involvement

Recent work by a number of researchers has further clarified the relationship between the independent, moderating and dependent variables. Two important variables to emerge from this literature are: 1) IS type and 2) User type, as having contingent effects on user satisfaction. Measurement of UIS should, a priori, be different depending upon the nature of the system with which users are being satisfied, and the tasks that the users perform (Goodhue 1988). Accordingly, a number of specific instruments or modifications to existing instruments have been developed and used.

The UIS instrument was developed during the period in which mainframe computing was the dominant platform of IS. All scales pertaining to IS product deal exclusively with output data, specifically: reliability, relevance, accuracy, precision and completeness. The remainder of the questions take the view that users are separate from the builders and that therefore the relationship between the two contains the source of satisfaction or dissatisfaction. More recently, because of developments in information technology, researchers have focused on the evaluation of specific types of information systems, introducing measures for decision support, ease of use, learnability etc. (Cats-Baril \& Huber 1987, Barki \& Huff 1985, Sanders \& Courtney 1985, Benbasat \& Dexter 1982). It is important to note that these studies have focused on specific properties of the respective type of systems and users. For example, the specific properties making up the success of DSS are related to the improvement of decision quality. Similarly studies related to success of end user computing (EUC) have been based on the basic premise that since end-users assume more responsibility for their own applications, their satisfaction should be measured through certain scales applicable to conventional computing environments, but also certain scales specific to EUC environment (Doll \& Torkzadeh 1988, Rivard \& Huff 1988).

As seen in Figure 1 systems can be classified according to a number of criteria. One broad distinction is based on the relationship that systems have with their organizational environment, specifically, either having an intra or inter-organizational focus. From an ontological perspective, it is reasonable to assume that different kinds of systems will have different stakeholders, different properties, and different criteria for evaluation. We would expect, therefore, that different kinds of systems within the same organization may be viewed differently by the same person.

Recent advances in national and international standards have promoted wider adoption of Electronic Data Interchange (EDI) systems. The orientation of class of system is external electronic linkage with trading partners $[4,14]$. EDI is recognized as a natural extension of interorganizational relations because it facilitates exchange of information and resources among the participating firms. Implementation and use of these systems are likely to lead to different perception and subsequent evaluation among users. With this view, it is possible to consider two broad classes of systems: those that are built having inter-organizational linkages as their primary focus, and those that have an intra-organizational focus. More specifically, we maintain that information systems can be classified in a hierarchy, composed of at least three components: a) properties shared by all IS, b) properties shared only by internal or external systems, but not both and c) properties unique to specific systems. The top level of the model covers the basic properties of all information systems. The intermediate level focuses on the unique properties that differentiate internal systems from the external ones. Finally, the bottom level relates to properties of specific information systems.

The framework in Figure 1 highlights the role of systems classification in the IS success assessment process. At the environment level, the parameter differentiating internal systems from external ones is related to the specificity of the internal environment as constrained by the internal operations, management and decision-making functions of the organization. At a specific system level, the success of a system is influenced by many specific factors unique to the system's functionality, economic goals and its stakeholders.

This leads to the following general hypothesis: 
H1: Managers evaluate the success of their internal systems differently than their external systems.

In addition to system type individual differences play an important role in the systems evaluation process (Zmud 1979). Users exist at all levels in organizations and interact with IS in a variety of ways. The central notion is that of fit between the technology and the job to be performed, whether it be decision making, data entry or other. Of interest in this study is the effect of respondent profile on the reported level of satisfaction. Specifically, the degree to which UIS scores vary across respondent groups reduces the ability to compare UIS surveys and hence stability and generality of the instrument. This leads to the following hypothesis:

H2: IS managers evaluate their IS differently than other functional area managers.

Being directly involved in development and management of systems, we would expect to see IS managers evaluating their systems higher than others. For our purposes it is sufficient to demonstrate the stability, or instability, of UIS measures among respondent groups.

\section{Figure 1. A classification model of information systems}

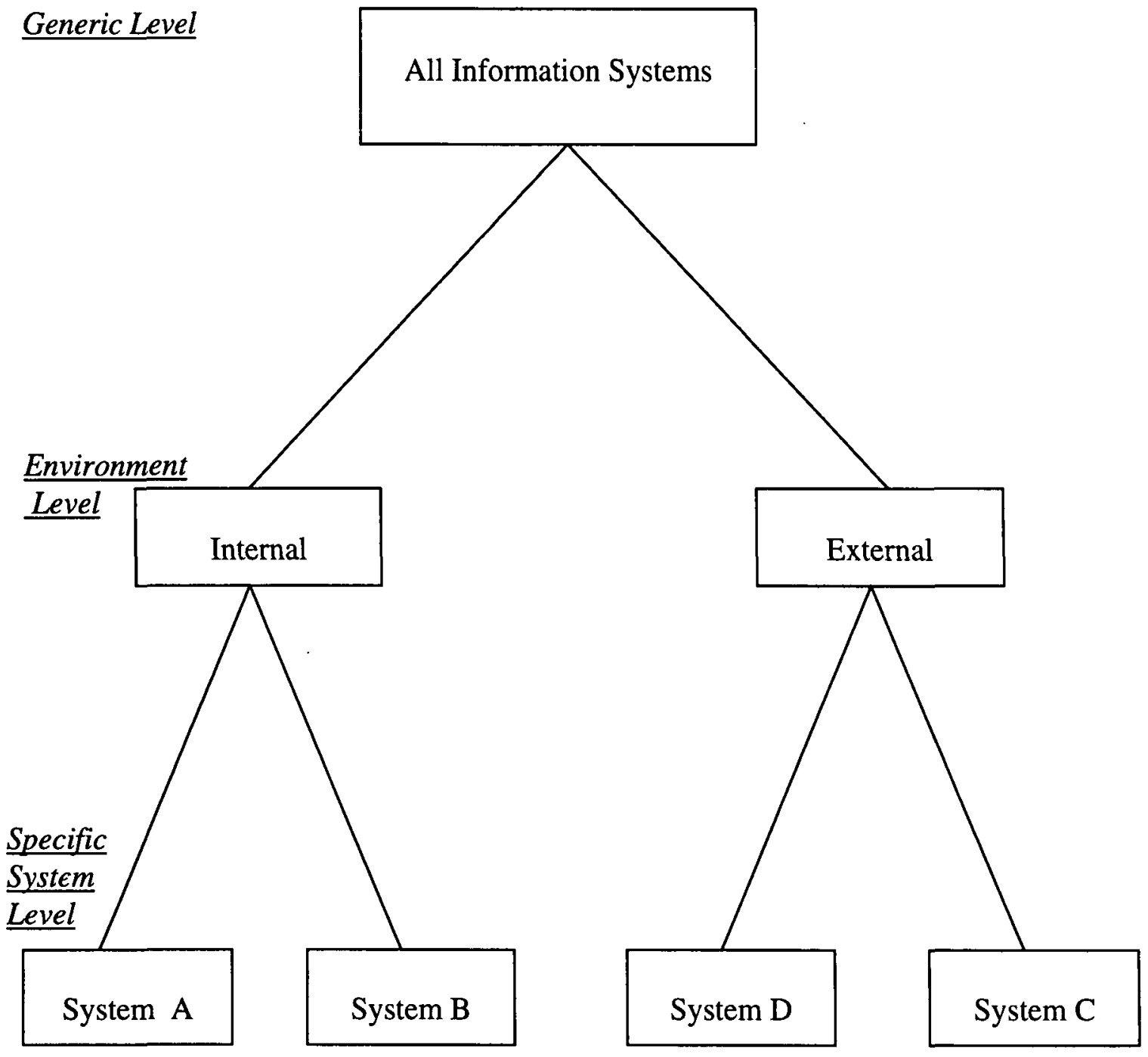




\section{SURVEY}

To investigate the research questions, which we have stated as hypotheses, a survey instrument was constructed comprising demographic questions, the standard 13 scale UIS questionnaire, and six additional questions. These six questions asked respondents to differentially evaluate their internal systems and their EDI program. Respondents were provided with the following definition of EDI at the beginning of the questionnaire:

$E D I$ is defined as the corporate to corporate exchange of business documents in a structured format. EDI is not electronic transmission of data in a free form. Therefore, it excludes facsimile $(F A X)$ transmission, which requires rekeying of data by the receiving party, and electronic mail (E-Mail), which requires rekeying or editing of data. However, it includes tape exchange of business documents in an EDI related format.

Respondents were requested to rate their internal systems and their EDI program according to three criteria each, namely:
1. Overall degree of success
2. The overall extent to which objectives are met
3. Overall satisfaction.

The complete instrument was designed, therefore, to measure managers' subjective evaluations of 1) all their computer based information systems (UIS instrument), 2) their internal systems (three questions), and b) their EDI systems (three questions).

The membership lists of the EDI Council of Canada and the Canadian Information Processing Society (CIPS) were used in the survey phase of the study. This questionnaire was mailed to 875 members of these two organizations. By the deadline, 208 usable questionnaires had been returned up to that date. In order to gain further insight into non-response bias, another wave of surveys was mailed out to 460 companies. The new mailing list was based on the one used in the final survey, but excluded the names of a) those who had responded to the survey and asked for the results (235), b) those on the undelivered envelopes (33), c) those who had not filled out the questionnaires for various reasons but returned it (15), and d) those who had indicated in the telephone follow-up that they were not interested in the survey (25). 78 questionnaires were received after the first deadline from the original mailing. By the second deadline, an additional 94 usable questionnaires were received, resulting on an overall usable response rate of $43 \%$ (379/875).

The questionnaires were divided into three groups, or waves, according to their dates of arrival. The first group contained all questionnaires that had been received before the deadline of the first mailing (208). The second group consisted of questionnaires received after that date (78). The last group contained the second mailing's surveys (94). These threc groups were cross tabulated with several demographics questions. The wave procedure assumes that late respondents are close in characteristics to nonrespondents. Evidence of no differences between the waves provides support for the assumption of group similarity, thercby allowing pooling of responses. In this survey, no evidence of non-response bias was found based on the firm's size, stage of EDI adoption, or respondents' functional area. None of the chisquare tests of independence could be rejected. The demographic information of the sample are shown in Tables 1-4.

Table 1: Distribution of firm size

\begin{tabular}{ccc}
\hline Annual Sales (Millions) & Frequency & Percent \\
\hline$<5$ & 30 & 8.8 \\
$\$ 5-\$ 9$ & 13 & 3.8 \\
$\$ 10-\$ 24$ & 30 & 8.8 \\
$\$ 25-\$ 49$ & 32 & 9.4 \\
$\$ 50-\$ 99$ & 28 & 8.3 \\
$\$ 100-\$ 249$ & 39 & 11.5 \\
$\$ 250-\$ 999$ & 60 & 17.7 \\
$\$ 1000$ or $>$ & 107 & 31.6 \\
\hline Total & 339 & 100.0 \\
\hline
\end{tabular}


Table 2: Industry classification

\begin{tabular}{lcccc}
\cline { 2 - 5 } & & & Cum. & Cum. \\
& Freq. & Percent & Freq. & Percent \\
\cline { 2 - 5 } Chemicals & 18 & 4.7 & 18 & 4.7 \\
Communications & 16 & 4.2 & 34 & 9.0 \\
Financial & 30 & 7.9 & 64 & 16.9 \\
Food Manufacturing & 27 & 7.1 & 91 & 24.0 \\
Government & 27 & 7.1 & 118 & 31.1 \\
Insurance & 14 & 3.7 & 132 & 34 \\
Metals, Mach. \& Equip. & 15 & 4.0 & 147 & 38.8 \\
Mining Oil \& Gas & 11 & 2.9 & 158 & 41.7 \\
Pharmaceutical \& Health & 17 & 4.5 & 175 & 46.2 \\
Printing \& Publishing & 14 & 3.7 & 189 & 49.9 \\
Pulp \& Paper & 9 & 2.4 & 198 & 52.2 \\
Retail Stores & 16 & 4.2 & 214 & 56.5 \\
Textile \& Apparel & 4 & 1.1 & 218 & 57.5 \\
Transportation & 23 & 6.1 & 241 & 63.6 \\
Utilities & 6 & 1.6 & 247 & 65.2 \\
Wholesale Trade & 23 & 6.1 & 270 & 71.2 \\
Other & 109 & 28.8 & 379 & 100.0 \\
\hline
\end{tabular}

Table 3: Stage of EDI adoption

\begin{tabular}{lcccc}
\hline & Freq. & Percent & $\begin{array}{c}\text { Cum. } \\
\text { Freq. }\end{array}$ & $\begin{array}{c}\text { Cum. } \\
\text { Percent }\end{array}$ \\
\cline { 2 - 6 } No EDI program underway & 111 & 29.3 & 111 & 29.3 \\
EDI Feasibility study & 45 & 11.9 & 156 & 41.2 \\
Technical Specifications & 12 & 3.2 & 168 & 44.3 \\
Legal \& audit requirements & 3 & 0.8 & 171 & 45.1 \\
Pilot program & 46 & 12.1 & 217 & 57.3 \\
EDI in operation mode & 162 & 42.7 & 379 & 100.0
\end{tabular}

Table 4: Respondent functional area

\begin{tabular}{lcccl} 
& & & Cum. & Cum. \\
& Freq. & Percent & Freq. & Percent \\
\cline { 2 - 5 } Finance & 44 & 11.6 & 44 & 11.6 \\
Information Systems & 205 & 54.1 & 249 & 65.7 \\
Production/Manufacturing & 5 & 1.3 & 254 & 67.0 \\
Purchasing & 15 & 4.0 & 269 & 71.0 \\
Sales/Marketing & 46 & 12.1 & 315 & 83.1 \\
Transportation/Logistics & 16 & 4.2 & 331 & 87.3 \\
Other & 48 & 12.7 & 379 & 100.0 \\
& & & & \\
\hline
\end{tabular}

\section{RESULTS}

The UIS literature over the years has repeatedly stressed the need for internal reliability of instruments. Galletta and Lederer (1989) present evidence that the test retest reliability of the UIS instrument may be weak, although, Hawk \& Raju (1991) challenge this evidence. One of the main concerns, however, is that the items used in the scales are internally consistent. In order to address the internal consistency issue, Table 5 compares the scale reliability of this study with the Baroudi \& Orlikowski (1988) study, and the 
Ives et. al. (1983) study ${ }^{28}$. As can be seen in Table 5, all the Chronbach's coefficients of alpha are in the acceptable range (higher than 0.90 ).

Table 5: UIS scale reliability comparison: chronbach's alpha

\begin{tabular}{|l|l|c|c|c|}
\hline \multicolumn{2}{|l|}{ UIS Scale } & This Study & $\begin{array}{c}\text { Baroudi } \\
\text { et. al }\end{array}$ & Ives et. al \\
\hline 1. & Relationship with MIS staff & .95 & .92 & .94 \\
\hline 2. & Processing of requests for changes & .94 & .88 & .90 \\
\hline 3. & Degree of MIS training provided & .95 & .93 & .97 \\
\hline 4. & User's understanding of systems & .94 & .88 & .92 \\
\hline 5. & User's feeling of participation & .91 & .89 & .92 \\
\hline 6. & Attitude of MIS staff & .95 & .92 & .88 \\
\hline 7. & Reliability of output information & .95 & .91 & .95 \\
\hline 8. & Relevancy of output information & .95 & .91 & .95 \\
\hline 9. & Accuracy of output information & .97 & .89 & .95 \\
\hline 10. & Precision of output information & .95 & .84 & .94 \\
\hline 11. & Communication with the MIS staff & .93 & .88 & .90 \\
\hline 12. & Time for new system development & .94 & .94 & .90 \\
\hline 13. & Completeness of the output & .97 & .93 & .96 \\
\hline Sample Size & & 330 & 358 & 100 \\
\hline
\end{tabular}

We factor analyzed the 13 scales of the UIS instrument in our sample data. For each of the 13 scales, the linear composite of the two corresponding items was calculated by averaging the 2 scores. The 3 -factor pattern was produced using varimax rotation. Table 6 presents this structure with the factor scores reported by Baroudi and Orlikowski (1988) in the adjacent column, surrounded by [].

\footnotetext{
${ }^{28}$ Although Raymond (1987) does not provide detailed scale reliability he reports that all alpha coefficients were between .81 and .95 .
} 
Table 6: Replicated three factor structure

\begin{tabular}{|l|l|ll|ll|ll|}
\hline \multicolumn{2}{|l|}{ UIS Scale } & \multicolumn{2}{l|}{$\begin{array}{l}\text { Information } \\
\text { Product }\end{array}$} & \multicolumn{2}{l|}{$\begin{array}{l}\text { MIS Staff \& } \\
\text { Services }\end{array}$} & \multicolumn{2}{l}{$\begin{array}{l}\text { Knowledge \& } \\
\text { Involvement }\end{array}$} \\
\hline 7. & Reliability of output information & .66 & {$[.82]$} & .35 & {$[.23]$} & .20 & {$[.11]$} \\
\hline 8. & Relevancy of output information & .60 & {$[.77]$} & .35 & {$[.00]$} & .27 & {$[.11]$} \\
\hline 9. & Accuracy of output information & .80 & {$[.82]$} & .23 & {$[.30]$} & .18 & {$[.13]$} \\
\hline 10. & Precision of output information & .79 & {$[.82]$} & .20 & {$[.28]$} & .16 & {$[.14]$} \\
\hline 13. & Completeness of the output & .63 & {$[.75]$} & .38 & {$[.30]$} & .24 & {$[.20]$} \\
\hline 1. & Relationship with MIS staff & .26 & {$[.24]$} & .77 & {$[.84]$} & .17 & {$[.09]$} \\
\hline 2. & Processing of change requests & .24 & {$[.15]$} & .58 & {$[.49]$} & .27 & {$[.49]$} \\
\hline 6. & Attitude of MIS staff & .31 & {$[.18]$} & .62 & {$[.82]$} & .18 & {$[.15]$} \\
\hline 11. & Communication with the MIS staff & .35 & {$[.21]$} & .75 & {$[.84]$} & .21 & {$[.11]$} \\
\hline 12. & Time for new system development & .28 & {$[.21]$} & .56 & {$[.49]$} & .35 & {$[.40]$} \\
\hline 3. & Degree of MIS training provided & .19 & {$[.23]$} & .41 & {$[.08]$} & .50 & {$[.82]$} \\
\hline 4. & User's understanding of systems & .23 & {$[.12]$} & $.19-$ & {$[.05]$} & .71 & {$[.80]$} \\
\hline 5. & User's feeling of participation & .27 & {$[.37]$} & .56 & {$[.37]$} & .54 & {$[.59]$} \\
\hline Eigen value & 3.04 & 3.57 & 3.19 & 3.02 & 1.58 & 2.20 \\
\hline Variance explained by factor & $24 \%$ & $28 \%$ & $25 \%$ & $28 \%$ & $12 \%$ & $17 \%$ \\
\hline
\end{tabular}

As can be seen the factor structures are strikingly similar, and there are small differences in the factor loadings. Appearing below each factor column is the factor's eigen value and the proportion of total variance explained by each factor. For the 3-factor structure in this study the explained variance is .61 , while the Baroudi and Orlikowski (1988) reported an explained variance of .68. An examination of the factor loadings and the relative eigen values indicates strong concordance between the two structures. Specifically, using the cut-off criteria of $.50,37$ of the 39 factor loadings match. The probability of this occurring by chance is less than .001. Further, the Fisher test applied to the equality of the factor variances could not be rejected at 001 .

We also compared the UIS mean scores across studies. It should be noted that different researchers have used different scales in their studies. For example, Raymond (1987) takes the average of two items reporting scores from 1 to 7, Galletta \& Lederer (1989), report scores scaled from 2 to 14 by summing the two items, while Baroudi \& Orlikowski (1988), re-scale the figures to fall between -3 and +3 . This later scale is more visually appealing as the zero point may be used to differentiate between unsatisfied and satisfied, assuming item midpoints are meaningful. Although all three scales are simple linear transformations, without the transformation, the job of comparison is much more abstruse. In this light we recalibrated previous mean satisfaction results to the -3 to +3 scale for comparison purposes.

Table 7 presents a comparison of five separate studies that used the UIS 13 scale instrument ${ }^{29}$. Several observations can be made about these five studies. First, the wide range of UIS Total satisfaction (-15.1 to +11.59 ) is reasonable considering that the questionnaire was administered to five different reference groups at different times. However, it is interesting that both low reports (Galletta \& Lederer and Raymond) were from MBA students and small firms respectively. Second, in the three studies that report detailed scales values, the lowest scores on all three are for the two questions relating to time: the Time for

\footnotetext{
${ }^{29}$ Since neither Baroudi \& Orlikowski (1988) or Joshi (1989) report detailed scale values, these have been marked with an '*'.
} 
new system development and the Processing of requests for changes. Clearly, time expectation has a negative effect on user satisfaction. The third observation of note is that the Information Product factor dominates positively across all studies. Perhaps a conclusion that can be drawn is that users are reasonably satisfied with the product once it is working, but are less pleased with the process of building or maintaining them. All in all, these results provide further evidence in support of the generalizability of the UIS instrument across different samples.

Table 7: UIS mean satisfaction scores comparison

\begin{tabular}{|c|c|c|c|c|c|c|}
\hline & & $\begin{array}{l}\text { This } \\
\text { Study }\end{array}$ & $\begin{array}{c}\text { Galletta \& } \\
\text { Lederer }\end{array}$ & Raymond & $\begin{array}{l}\text { Baroudi \& } \\
\text { Orlikowski }\end{array}$ & Joshi \\
\hline \multicolumn{7}{|c|}{ System Product Factor } \\
\hline 7. & Reliability of output information & 1.29 & -0.40 & -1.03 & * & * \\
\hline 8. & Relevance of output information & 1.27 & -0.45 & -0.96 & $*$ & * \\
\hline 9. & Accuracy of output information & 1.72 & 0.05 & -0.86 & * & $*$ \\
\hline 10. & Precision of output information & 1.37 & -0.50 & -0.92 & * & $*$ \\
\hline 13. & Completeness of the output & 1.03 & -1.00 & -1.31 & $*$ & * \\
\hline \multicolumn{2}{|c|}{ Factor Total } & 1.34 & -0.46 & -1.01 & 1.30 & 1.08 \\
\hline \multicolumn{7}{|c|}{ MIS Support \& Services Factor } \\
\hline 1. & Relationship with MIS staff & 1.22 & -0.45 & -0.92 & * & * \\
\hline 2. & Processing of requests for changes & 0.16 & -2.50 & -1.58 & * & * \\
\hline 6. & Attitude of MIS staff & 1.15 & -.070 & -0.91 & * & * \\
\hline 11. & Communication with the MIS staff & 1.15 & -.050 & -1.08 & * & $*$ \\
\hline 12. & Time for new system development & -0.05 & -2.45 & -1.67 & * & * \\
\hline \multicolumn{2}{|c|}{ Factor Total } & 0.73 & -1.32 & -1.23 & 0.20 & 0.34 \\
\hline \multicolumn{7}{|c|}{ User Involvement Factor } \\
\hline 3. & Degree of MIS training provided & 0.17 & -1.5 & -1.55 & * & * \\
\hline 4. & User's understanding of systems & 0.44 & -1.3 & -1.25 & $*$ & $*$ \\
\hline 5. & User's feeling of participation & 0.67 & -1.7 & -1.08 & $*$ & $*$ \\
\hline \multicolumn{2}{|c|}{ Sample Size } & 330 & 27 & 464 & 358 & 100 \\
\hline \multicolumn{2}{|c|}{ Subjects } & Mangers & $\begin{array}{c}\text { MBA } \\
\text { Students }\end{array}$ & $\begin{array}{c}\text { Small } \\
\text { Manufac. }\end{array}$ & Clerical & Prod. Man. \\
\hline
\end{tabular}

In order to test the first research hypothesis, we used matched paired t-test of the respondents evaluation of their internal and EDI systems, using the three variables related to overall system success, objectives, and satisfaction (Table 8 ). ${ }^{30}$ We accounted for the firm size by dividing the sample into small and large firms. The larger number of missing values for small firms is due to the lower frequency of EDI programs in small companies.

\footnotetext{
${ }^{30}$ A positive difference indicates higher satisfaction with internal systems.
} 
Table 8: Evaluation differences

\begin{tabular}{|c|c|c|c|c|c|c|c|}
\hline \multicolumn{8}{|c|}{ Firm Size $<\$ 100 M$} \\
\hline $\mathbf{N}$ & Variable & $\mathrm{N}$ & Nmiss & Mean & Std Error & $\mathbf{T}$ & Prob $>|T|$ \\
\hline \multirow[t]{3}{*}{173} & DIFF_SUC & 57 & 116 & 0.49 & 0.12 & 3.99 & .000 \\
\hline & DIFF_OBJ & 59 & 114 & 0.58 & 0.14 & 4.02 & .000 \\
\hline & DIFF_SAT & 59 & 114 & 0.25 & 0.14 & 1.87 & .066 \\
\hline \multicolumn{8}{|c|}{ Firm Size $>\$ 100 M$} \\
\hline $\mathrm{N}$ & Variable & $\mathbf{N}$ & Nmiss & Mean & Std Error & $\mathrm{T}$ & Prob $>|\mathrm{T}|$ \\
\hline \multirow[t]{3}{*}{206} & DIFF_SUC & 142 & 64 & 0.18 & 0.08 & 2.23 & .027 \\
\hline & DIFF_OBJ & 138 & 68 & 0.63 & 0.09 & 6.77 & .000 \\
\hline & DIFF_SAT & 141 & 65 & 0.26 & 0.08 & 3.11 & .002 \\
\hline
\end{tabular}

The results clearly indicate differences between manager's evaluations of their systems based solely on system classification. One further observation is appropriate. In all cases the evaluation of internal systems is higher than for external systems. We may speculate that familiarity with existing systems may lead to more favourable responses, and that in time, any unfavourable evaluations of EDI systems due to, for example, uncertainty, time delays etc., will ameliorate. This, however, goes beyond the current data and remains a topic for further investigation.

To test the second hypothesis the sample was divided into two groups: IS Managers and all other managers. The results of this test appear in Table 9. Non-parametric tests were performed on all variables. Not surprisingly, IS managers report significantly higher UIS scores than other managers, perhaps providing prima facie evidence for key respondent bias. Several observations are worthwhile. First, ten of the thirteen UIS scales show clear differences in levels of satisfaction; Precision of Output, Degree of Training, and User's Understanding being the notable exceptions. Second, IS managers' evaluations dominate on all UIS summary questions. Third, the largest discrepancies come from the MIS Attitude and Time for System Development items, both being process measures.

\section{SUMMARY}

This paper has examined several structural aspects of the 13 scale UIS instrument. Comparison of these results with four previous studies indicates that users are relatively more satisfied with the products of system development than they are with the process of system development. Within this sample of respondents, significant differences in level of satisfaction were detected when respondence functional area is taken into account. Specifically, IS managers were, not surprisingly, more satisfied with their systems than non-IS managers. Further, managers rated the success of their intra-organizational systems higher than their inter-organizational systems.

We would like to point out some of the issues that subsequently need to be addressed. First, as IS products have made steady improvement in quality, this dimension of satisfaction may be becoming increasingly related to satisfaction with the IS development process. In this light we need to directly question the assumption of orthogonality of the three factors and use structural modelling techniques to test higher order structures underlying UIS. In the process we need to understand that the UIS factor structure is not in itself a final research result. Rather, each of the underlying dimensions must be translated into management agendas for change if the objective is to improve satisfaction, rather than simply accepting it. 
Table 9: Respondent differences

\begin{tabular}{|c|c|c|c|c|}
\hline & & $\begin{array}{l}\text { IS Managers } \\
(n=205)\end{array}$ & $\begin{array}{l}\text { Non-IS } \\
\text { Managers } \\
(n=174) \\
\end{array}$ & Prob $>|\mathrm{T}|$ \\
\hline \multicolumn{5}{|c|}{ System Product Factor } \\
\hline 7. & Reliability of output information & 1.47 & 1.07 & .010 \\
\hline 8. & Relevancy of output information & 1.41 & 1.10 & .032 \\
\hline 9. & Accuracy of output information & 1.83 & 1.59 & 055 \\
\hline 10. & Precision of output information & 1.45 & 1.28 & .240 \\
\hline 13. & Completeness of the output & 1.26 & .77 & .001 \\
\hline \multicolumn{5}{|c|}{ MIS Support \& Services Factor } \\
\hline 1. & Relationship with MIS staff & 1.37 & 1.05 & .058 \\
\hline 2. & Processing of requests for changes & 0.42 & -0.15 & .004 \\
\hline 6. & Attitude of MIS staff & 1.40 & 0.84 & .000 \\
\hline 11. & Communication with the MIS staff & 1.29 & 0.98 & .047 \\
\hline 12. & Time for new system development & 0.26 & -0.44 & .000 \\
\hline \multicolumn{5}{|c|}{ User Involvement Factor } \\
\hline 3. & Degree of MIS training provided & 0.31 & -0.01 & .121 \\
\hline 4. & User's understanding of systems & 0.48 & 0.38 & .621 \\
\hline 5. & User's feeling of participation & 0.88 & 0.42 & .004 \\
\hline \multicolumn{5}{|c|}{ Summary Questions } \\
\hline \multicolumn{2}{|c|}{ IS Product } & 1.23 & 0.83 & .010 \\
\hline \multicolumn{2}{|c|}{ MIS/EDP Staff and Services } & 1.25 & 0.56 & .000 \\
\hline \multicolumn{2}{|c|}{ User Knowledge and Involvement } & 1.43 & 0.64 & .000 \\
\hline \multicolumn{2}{|c|}{ Overall Satisfaction } & 1.14 & 0.54 & .001 \\
\hline \multicolumn{2}{|c|}{ UIS Total $(-39$ to +39$)$} & 13.75 & 8.93 & .001 \\
\hline
\end{tabular}

\section{REFERENCES}

Bailey, J.E., \& Pearson, S.W. Development of a Tool for Measuring and Analyzing Computer User Satisfaction, Management Science, Volume 29, Number 5, May 1983, 530-545.

Barki, H., \& Huff, S. L. Change, Attitude to Change, and Decision Support System Success, Information \& Management, 1985. Pages 261-268.

Baroudi, J. J. \& Orlikowski W.J., A Short-Form Measure of User Information Satisfaction: A Psychometric Evaluation and Notes on Use, Journal of Management Information Systems, Vol. 4 No. 4, Spring 1988, 44-59. 
Barrett S. and Konsynski B. Inter-Organization Information Sharing Systems, MIS Quarterly, September 1982, 93-105.

Benbasat, I., and Dexter, A. Individual Differences in the Use of Decision Support Aids, Journal of Accounting Research, Spring 1982, 1-11.

Cats-Baril, W. L. and Huber, G. Decision Support Systems for Ill-Structured Problems: An Empirical Study, Decision Sciences, Summer 1987, 350-372.

Chroust, G.; Goldmann H.; Gschwandtner, O., The Role of Work Management in Application Development, IBM Systems Journal, Vol. 29, No. 2, February 1990, 189-208.

Delone, W. H. and McLean, E. M., Information Systems Success: The Quest for the Dependent Variable, Information Systems Research, March 1992, 60-95.

Doll, W. J., and Torkzadeh, G. The Measurement of End-User Computing Satisfaction, MIS Quarterly, June 1988, 259-274.

Gallagher, C. Perception of the Value of a Management Information System, Academy of Management Journal, 17, 1, 1974, 46-55.

Galletta, D. F. \& Lederer, A. L., Some Cautions on the Measurement of User Information Satisfaction, Decision Sciences, Vol. 20, 1989, 419-438.

Goodhue, D., I/S Attitudes: Toward Theoretical and Definitional Clarity, Database, Fall/Winter 1988, Vol. 19 No. 3/4, 6-15.

Hawk, S. R., \& Raju N.S., Test-Retest Reliability of User Information Satisfaction: A Comment on Galletta and Lederer's Paper, Decision Sciences, Vol. 22, 1991, 1165-1170.

Horner R. B. \& Benbasat I. An Empirical Investigation of Factors Influencing the Success of Customer-Oriented Strategic Systems, Information Systems Research, September 1990, 325-347.

Ives B., Olson M. \& Baroudi J. The Measurement of User Information Satisfaction, Communications of the ACM, Vol. 26, No. 10, 1983, 785-793.

Joshi, K., An Investigation of Equity as a Determinant of User Information Satisfaction, Decision Sciences, Vol. 21, 1990, 786-807.

Lanphar, R., Quantitative Process Management in Software Engineering, a Reconciliation Between Process and Product Views, Journal of Systems \& Software, Vol. 12, No. 3, July 1990, 243-248.

Madhavji, N. H., Schafer, W., Prism - Methodology and Process-Oriented Environment, IEEE Transactions on Software Engineering, Vol. 17, No. 12, December 1991, 1270-1283.

Montazemi, A. R. Factors Affecting Information Satisfaction in the Context of Small Business Environment, MIS Quarterly, Vol. 12, No. 2, 1988, 239-258.

Pfleeger, Shari Lawrence, McGowan, Clement, Software Metrics in the Process Maturity Framework, Journal of Systems \& Software, Vol. 12, No. 3, July 1990, 255-261.

Raymond, L. Validating and Applying User Satisfaction as Measure of MIS Success in Small Business Organizations, Information and Management, No. 12, 1987, 173-179.

Rivard, S. and Huff, S. Factors of Success of End User Computing, Com. ACM, May 1988, $552-561$.

Rombach, H. Dieter, Ulery, Bradford T., Valett, Jon D., Toward Full Life Cycle Control: Adding Maintenance Measurement to the SEL, Journal of Systems \& Software, Vol. 18 No. 2, May 1992.

Sanders, L. G., and Courtney, J. F. A Field Study of Organizational Factors Influencing DSS Success, MIS Quarterly, March, 1985. Pages 77-89.

Software Engineering Journal, Special Edition on Software Process and its Support, edited by Madhavji, N. H., Vol. 6, No. 5, September 1991.

Tate, G.; Verner, J.; Jeffery, R., CASE: A Testbed for Modeling, Measurement and Management, Communications of the ACM, Vol. 35, No. 4, April 1992, 65-72.

Zmud, R. Individual Differences and MIS Success: A Review of the Empirical Literature, Management Science, Vol. 10 No. 10., October 1979, 966-979. 